
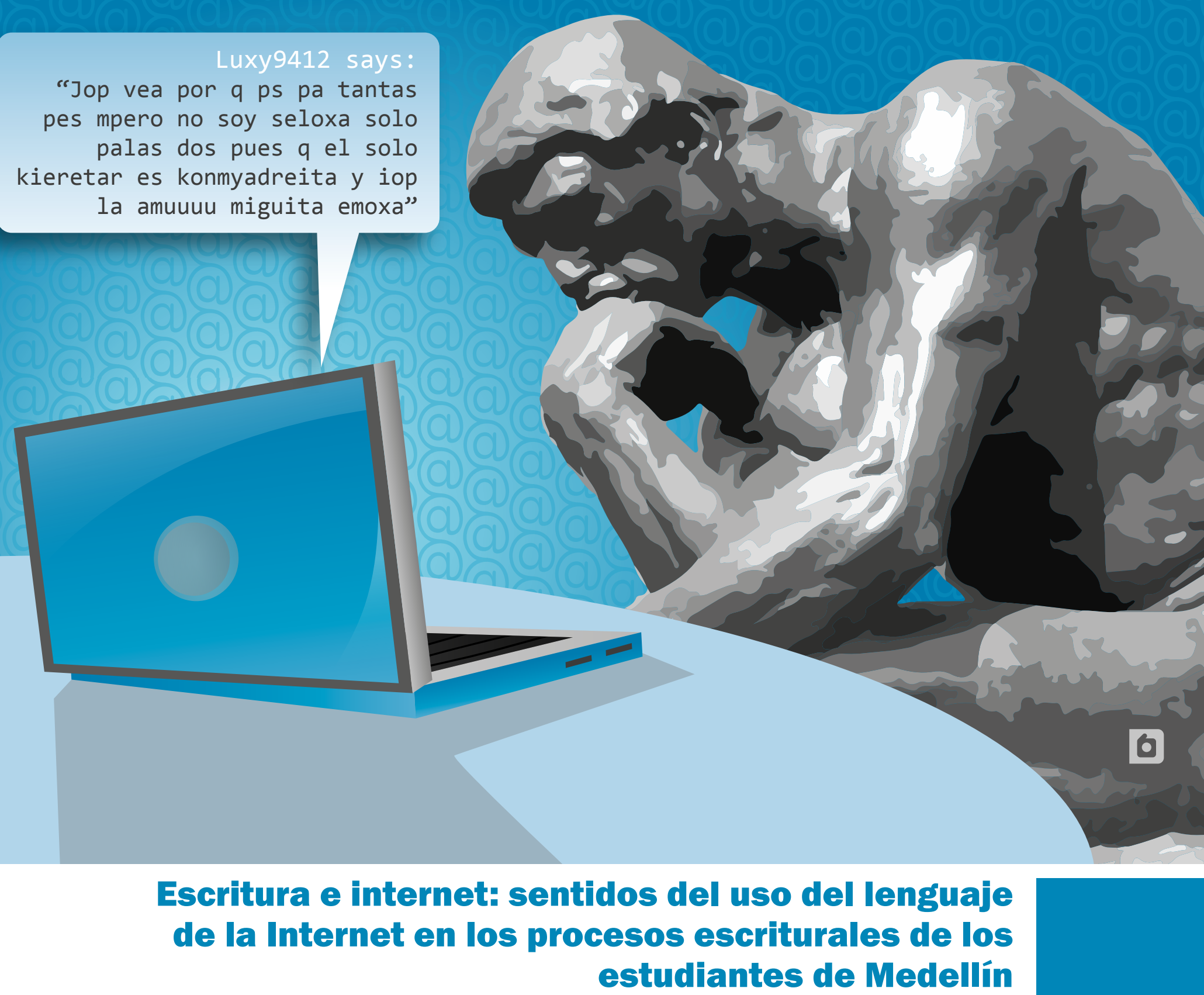

Writing and the internet: senses of language use of the Internet in the scriptural processes students Medellín

Escrita e da internet: formas de utilizar a linguagem da Internet nos processos de escrituras aos alunos Medellín

Milton Daniel Castellano Ascencio / milton.castellano@usbmed.edu.co Ena Luz Ortiz Naranjo / eluorna@gmail.com 
Milton Daniel Castellano Ascencio ${ }^{1}$ milton.castellano@usbmed.edu.co

Ena Luz Ortiz Naranjo ${ }^{2}$ eluorna@gmail.com
1 Magister en Lingüística de la Universidad de Antioquia; estudiante de Doctorado en Lingüística. Director de la Línea Pedagogía, Lenguaje y Comunicación e investigador del grupo Estudios Interdisciplinarios sobre Educación de la Universidad de San Buenaventura, seccional Medellín.

2 Magister en Educación de la Universidad de San Buenaventura, seccional Medellín.

Fecha de recepción: 17 de octubre de 2013 / Fecha de aprobación: 8 de noviembre de 2013

\section{Escritura e internet: sentidos del uso del lenguaje de la Internet en los procesos escriturales de los estudiantes de Medellín}

\section{Resumen}

El presente texto analiza las representaciones de sentido que se generan en los procesos escriturales de los estudiantes de Medellín, influenciados por el uso del Netspeak; el diseño metodológico corresponde a una investigación cualitativa con enfoque fenomenológico. En el artículo se resalta que el Netspeak es un rasgo identitario de los estudiantes medellinenses, pues este lenguaje hace parte de su vida, lo cual justifica que sus producciones escritas lo incorporen con el fin de comunicar distintos sentidos sobre lo cotidiano y sobre su condición de sujetos comunicantes.

Palabras clave: escritura, Netspeak, nativos digitales, redes sociales, representaciones de sentido.

\section{Writing and the internet: senses of language use of the Internet in the scriptural processes students Medellín}

\section{Summary}

This article discusses the representations of sense generated in the writing of Medellin students, influenced by the frequent use of netspeak. The research design is phenomenological because this approach seeks to understand the social phenomena that are presented with unique features and originate in specific contexts. The article highlight that among the range of identitary features characteristic of digital natives is the netspeak, like language that identifies this generation and is part of life world of students netizen.

Keywords: Digital Natives, netspeak, representations of sense, social networks, writing.

\section{Escrita e da internet: formas de utilizar a linguagem da Internet nos processos de escrituras aos alunos}

\section{Medellín}

Resumo

0 artigo analisa as representações de sentido gerada nos processos escriturais dos estudantes de Medellin, influenciados pelo netspeak. Quanto ao desenho metodológico, corresponde a uma pesquisa de abordagem fenomenológica. No artigo se destaca que o netspeak é uma questão relacionada com a construção da identidade dos estudantes, pois esta linguagem faz parte do mundo da vida cotidiana dos alunos, o que justifica a presença do netspeak na escrita deles y na expressão de sentidos diferentes que tem relação com suas vivências y com sua propria condição de sujeitos comunicantes.

Palavras-chave: nativos digitais, netspeak, redes sociais, representações de sentido. 


\section{Consideraciones iniciales}

El uso de las nuevas tecnologías de la información y la comunicación (NTIC) es cada vez más frecuente, sobre todo en lo relacionado con la utilización de la Internet, pues ésta se ha convertido en un instrumento cotidiano en la vida de hombres y mujeres del mundo en general, pues facilita la comunicación y el intercambio de información. Además, la Internet ha permeado otros espacios de la vida de este siglo, como por ejemplo el espacio político, donde se utilizan las NTIC para posibilitar encuentros de participación ciudadana, o el espacio económico, donde los usuarios o empresarios tienen la posibilidad de comprar, vender, intercambiar y expandir su productos sin necesidad de desplazarse. Así mismo, la Internet y las NTIC en general facilitan el acceso a la información, y también la realización de actividades cotidianas como comprar, organizar, gestionar las vacaciones, etc., lo cual ha hecho que de algún modo estos medios ocupen un espacio de importancia en el tiempo de las personas, y se conviertan en nuevos distractores para los momentos de ocio, por lo menos para las generaciones más jóvenes.

De igual forma, las NTIC han posibilitado que la comunicación sea instantánea y percibida como una forma que vincula lo oral y lo escrito en un tiempo real, característica que está representada en las denominadas redes sociales como Twitter, Facebook, Messenger, What's Up, Hi5, entre otras, que son frecuentadas por los cibernautas y que suponen una nueva forma de interacción y de socialización.

En ese sentido, el hecho de que la Internet, a nivel general, y las redes sociales, desde lo particular, se consideren espacios de socialización, y tengan una alta presencia dentro de las nuevas generaciones de ciudadanos, ha hecho que las nuevas tecnologías encuentren un camino expedito en el ámbito educativo. Así, las instituciones educativas se constituyen en otro espacio que ha sido permeado por las NTIC, en cuanto que han incorporado paulatinamente estos medios como facilitadores de la enseñanza y del aprendizaje. Desde este punto de vista, la Internet y las NTIC han pasado a ser parte de la vida cotidiana de docentes y estudiantes.

Sin embargo, la incorporación de estas herramientas no sólo supone retos relacionados con la inclusión de la tecnología al ámbito educativo, sino que crea problemáticas relacionadas con los procesos educativos de los estudiantes. Un ejemplo lo encontramos en algunas instituciones educativas de Medellín, donde se han venido observando cambios frecuentes en los procesos escriturales de los estudiantes por causa del uso frecuente de la Internet, específicamente de las distintas redes sociales. Estos cambios introducidos en la escritura por causa del uso de las redes sociales, van desde el desconocimiento de asuntos relacionados con la gramática hasta la generación de códigos que restringen la comprensión de los mensajes que se comunican. A modo de ejemplo, presentamos el siguiente texto construido por un estudiante, donde se observan algunos de los cambios que con frecuencia se introducen en la escritura: "Jop vea por q ps pa tantas pes mpero no soy seloxa solo palas dos pues q el solo kieretar es konmyadreita y iop la amuuuu miguita emoxa".

En el ejemplo vemos sustituciones de grafías: $g$ y c suelen ser reemplazadas por $\mathrm{k}$; s por $\mathrm{z}, \mathrm{y}$ z por $\mathrm{x}$; además, se evidencia la utilización de abreviaturas, combinación de palabras separadas, repetición de letras, entre otras. Esta forma de expresarse de los estudiantes en las redes sociales, no sólo se observa en dicho espacio, sino también en las producciones escritas que realizan en el marco de sus actividades académicas o en cualquier otro espacio que implique la escritura. Situación que supone ciertos retos y problemáticas para los docentes, que van, desde la dificultad para comprender lo que quieren expresar sus estudiantes, debido a la alta presencia de códigos restringidos o de un lenguaje críptico que sólo es compresible para quienes están inmersos en el medio digital, hasta preguntarse por los motivos de estas manifestaciones lingüísticas en el marco de la comunicación escrita, que por tradición tienen un alto nivel de formalidad y un hálito prescriptivo.

Sin embargo, estas formas escriturales de los estudiantes no se pueden considerar simplemente como un vicio gramatical que va en detrimento de una comunicación asertiva, o como una limitación de la competencia pragmática de los estudiantes, en la medida en que a partir de dicha traslación, no hacen un reconocimiento de la situación comunicativa en la que se ven inmersos, sino que conservan un único registro para cualquier situación comunicativa.

Estas transformaciones también hablan de la brecha generacional entre los actores del proceso educativo y de la manera como los estudiantes se relacionan con su mundo de la vida, con las nuevas realidades que surgen en él, y las representaciones de sentido que han construido sobre diferentes asuntos; las mismas, dejan de ser una simple representación de un objeto sin más, en la memoria, una reproducción idéntica de una cosa u objeto del mundo exterior en la memoria, y ahora implican significados. Esto porque una representación "no es el duplicado de lo real, ni el duplicado de lo ideal [sino que hay que buscar detrás de las representaciones] los procesos por [los cuales] se establece su relación [también] debemos buscar esta relación con el mundo y con las cosas" (Jodelet, 1986, p. 475). 
Es cierto que a través de la historia los jóvenes han creado su propia identidad, sus propias formas o códigos de comunicación oral y escrita, lo que de alguna manera les ha diferenciado de las generaciones anteriores, sin embargo, esta generación del siglo XXI, a la que pertenecen los estudiantes que habitan las instituciones educativas en Medellín, ha marcado una pauta diferente, en cuanto que ha nacido inmersa en el auge de las NTIC; son los jóvenes actuales los que han construido su propia identidad, su propio espacio y han recreado sus propios códigos lingüísticos, los cuales han perdu-

\section{Consideraciones metodológicas}

El trabajo desarrollado corresponde a una investigación cualitativa, pues profundiza en las realidades subjetivas de los sujetos en su mundo y, desde ahí, ofrece elementos que ayudan a alcanzar los objetivos y fundamentar el problema de interés. En este sentido, Galeano (2003) afirma que el enfoque cualitativo de investigación social aborda las realidades subjetivas e intersubjetivas como objetos legítimos de conocimientos científicos; busca comprender -desde la interioridad de los actores sociales- las lógicas de pensamiento que guían las acciones sociales (pp. 16-18). De igual forma, esta investigación se fundamenta en el enfoque fenomenológico, pues busca entender fenómenos sociales con características únicas, y originados en contextos específicos, que son modificados por hombres y mujeres, y llenados de significado en su vida cotidiana.

El contexto corresponde al de las instituciones educativas, públicas y privadas, de Medellín en las que se ha identificado el fenómeno de la transferencia del lenguaje de la Internet a las producciones escritas de los estudiantes. De esta forma, los suje-

\section{Consideraciones teóricas}

\subsection{Netspeak o lenguaje de Internet}

El Netspeak o lenguaje de la Internet, es un componente importante en esta investigación, en cuanto que algunos elementos de dicho lenguaje son utilizados con frecuencia por los estudiantes en sus producciones escritas en el contexto escolar; sin embargo, vale la pena aclarar que en este artículo no se pretende realizar un estudio exhaustivo del lenguaje de la Internet, sólo rado más tiempo si se comparan con otras generaciones. Es a esta generación a la que Prensky (2001) y Piscitelli (2009), denominan "nativos digitales".

Por todo lo anterior, resulta pertinente e interesante analizar cuáles son los sentidos que se han venido generando en los procesos escriturales de los estudiantes de Medellín, influenciados por el uso frecuente del lenguaje de la Internet o lenguaje digital. En este sentido, el presente artículo se ha propuesto como objetivo describir y analizar las representaciones de sentido que se generan en los estudiantes medellinenses al utilizar el Netspeak.

tos participantes en la investigación fueron seleccionados a partir de la aplicación de una encuesta que permitió determinar la frecuencia con que utilizaban las redes sociales, el tiempo que permanecían conectados a las mismas, el tipo de redes sociales frecuentadas, el conocimiento y uso del lenguaje de la Internet $y$, principalmente, si utilizaban o no dicho lenguaje en sus producciones escriturales. Se seleccionaron los sujetos teniendo en cuenta un criterio de frecuencia alta sobre los aspectos que incluía la encuesta y la intención de participación de los estudiantes en el proceso de investigación.

En cuanto a los instrumentos de recolección de información, se ha considerado la entrevista semiestructurada, el grupo de discusión y la observación no participante, pues, según Miguélez (2004): “con dicha observación fenomenológica se pretende observar y registrar la realidad con una profunda concentración y una ingenuidad disciplinada'. Abrir bien los ojos, y mantenerlos así, mirar y escuchar con toda atención y poner todos los sentidos en el asunto” (p. 144).

se retomarán elementos relacionados con los cambios que nos permitan acercarnos a los significados que subyacen en el uso que los estudiantes hacen de este lenguaje.

Para comenzar, será necesario remitirse a uno de los lingüistas que ha investigado el tema, el Irlandés David Crystal (2002), quien en su libro Lenguaje de internet, ha abordado puntos fun- 
damentales de manera clara y muy detallada. Para Crystal el Netspeak, como lo ha llamado, es una forma de comunicación interesante porque se nutre de características que pertenecen al lenguaje oral y al lenguaje escrito; por ejemplo, el lenguaje oral está representado en las construcciones de oraciones más sueltas, también en la presencia abundante de neologismos, combinaciones y acortamientos de palabras separadas, y repeticiones de elementos (términos como "así que", y "fin de semana", son combinados por los chicos y chicas cibernautas: "Asique", "finde"); también la repetición de letras, (como en "holllllaaaaaa. Mmmuuuaaaaaaakkkkkk"), y demás combinaciones utilizadas por los jóvenes, tales como "Queueno Te IdentifiQas Al Igual Qeee Yo!! Jeje QeQosas ;) [Guiño]”, o suplir un elemento de una palabra por otros que sean fonéticamente equivalentes: "S2S=sisas, o F2F=cara a cara"; también las disociaciones que se aplican al prefijo, escribiéndolo separado del mismo, por ejemplo "re ke, re linda, re vieja, toy reee bn", dan cuenta de características únicas e interesantes que se entremezclan en el Netspeak.

Otro de los fenómenos que trae consigo el lenguaje de la Internet es el de los "errores ortográficos", sobre los que Crystal (2002), afirma que no distraen del contexto del mensaje, dada la relativa brevedad de la oración; a la vez, los mensajes escasamente puntuados plantean pocos problemas de ambigüedad, y el receptor no va a cuestionar la credibilidad del mismo o de la persona que cometa errores ortográficos, porque, de alguna manera, conoce las condiciones en que se escribe dicho mensaje, es decir, entre los interlocutores hay una conciencia pragmática que permite considerar como adecuadas ciertas construcciones que en otros contextos podrían catalogarse como problemáticas o agramaticales, y que en el contexto de la Internet son totalmente válidas, pertinentes y están cargadas de sentido o de significación.

Sin embargo, los signos ortográficos han sido afectados en el lenguaje; entre ellos, la mayúscula que, para Crystal (2002), ha adquirido un uso y un significado diferente debido a que la Internet no tiene en cuenta el cuerpo de la letra, por lo que en el Netspeak se utilizan las minúsculas para casi todos los enunciados, pues se aplica el método de "ahorrarse una tecla", y desde este "método" se puede construir todo tipo de oraciones sin utilizar mayúsculas. También existe la mentalidad entre los cibernautas de que la utilización de las mayúsculas da una marcación extrema o exagerada de la comunicación, es decir, en la Internet su uso es una forma de indicar aspectos prosódicos a través de la escritura, equivalente a un tono alto de habla o al grito, por eso los usuarios prefieren evitarlas en sus construcciones.
Todas estas formas escriturales de los estudiantes nativos digitales en la Internet, son las que también circulan en los cuadernos de los estudiantes cibernautas, lo que indica que dicho lenguaje se ha introducido en la vida de los jóvenes. Esta forma de escritura no solamente se restringe a un principio de economía lingüística o está asociada a un mecanismo de comunicación que se adapta a la velocidad de los intercambios comunicativos en la Internet; también da cuenta de construcciones de sentido que condensan en pocas palabras lo que se quiere trasmitir al otro, al tiempo que lo hace con una serie de construcciones o representaciones semánticas elaboradas por los estudiantes a partir de diferentes aspectos de su realidad, las mismas que, de una u otra forma, hablan de huellas identitarias implícitas en las características, y sobre todo en la intencionalidad, de la escritura en los nativos digitales.

Por su parte, en La Ciberpragmática, el uso del lenguaje en Internet, el lingüista español Francisco Yus (2001), quien también ha aportado desde la pragmática al estudio del uso del lenguaje en la Internet, aborda el papel de las posibilidades de interactividad en las peculiaridades de la comunicación entre los usuarios. El autor trata de aplicar todo el aparato teórico de la pragmática al discurso de los usuarios de la Internet, lo cual ha sido útil para la explicación de la comunicación entre personas en situación de co-presencia física de los interlocutores y en situaciones de sincronía comunicativa. Según Yus (2001), la comunicación mediante la Internet está basada en el intercambio masivo del mensaje de texto, pero con una clara vocación oral, lo que convierte esta variedad interactiva en un interesante híbrido: por un lado, entre estabilidad y rigidez del soporte escrito, y por otro, entre la espontaneidad y cualidad efímera del habla.

Yus (2001, p. 12), afirma que el aspecto más sobresaliente de esta comunicación electrónica es la oralidad del texto, entendida como la sensación para los usuarios de escribir lo que desearían estar diciendo y leer lo que les gustaría estar oyendo, lo cual origina alguna manera toda una gama de estrategias comunicativas que deberían estudiarse desde una perspectiva pragmática: una concepción de la escritura que tenga en cuenta su uso real, o al menos una idea de la comunicación en situación real, no vista desde lo que establece la enseñanza tradicional o convencional.

Por otro lado Palazzo (2009), establece una serie de consideraciones que se basan en el estudio de los jóvenes como usuarios de los nuevos géneros del ciberespacio, a partir de los efectos sociales que han promovido las distintas prácticas discursivas propias de los nuevos medios de comunicación. Así, propone una categoría de análisis denominada el "ciberdiscurso juvenil", 


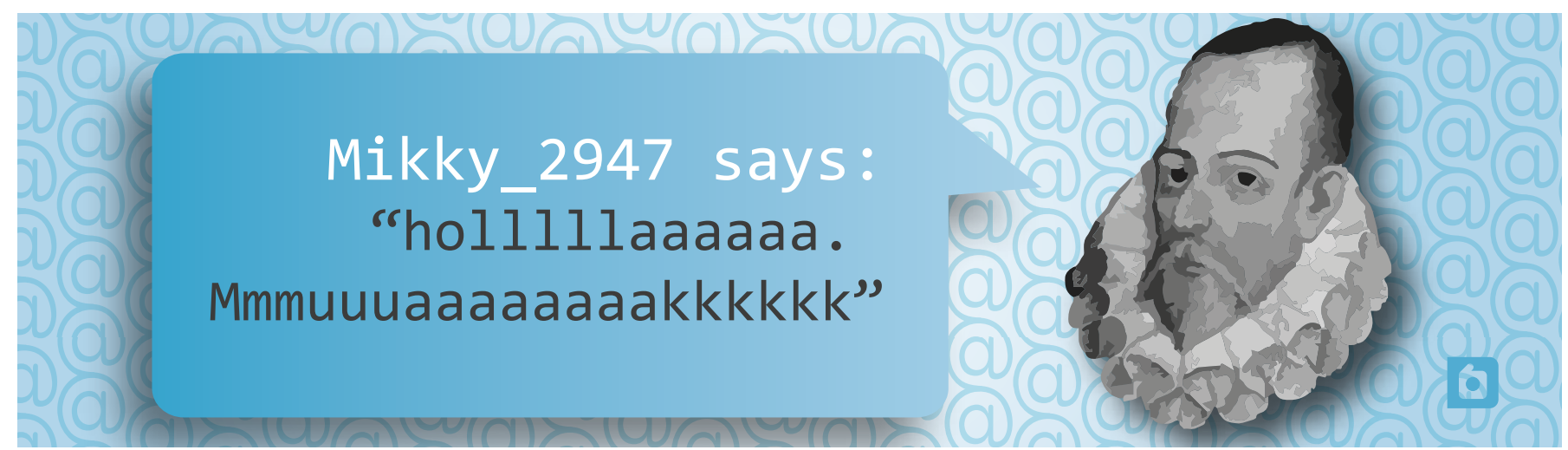

la cual corresponde a una forma de discurso representada en la combinación de signos verbales y no verbales empleados en el contexto de las redes sociales o del ciberespacio, donde se dan las particularidades en la construcción discursiva del "ciberhabla".

Estas consideraciones sobre el Netspeak, desde la perspectiva lingüística, hacen evidente que las transformaciones en la lengua no sólo tienen una intención críptica, aspecto habitual en el lenguaje juvenil, sino que también vinculan elementos identitarios que hablan principalmente de cohesión y pertenencia grupal, pues sólo es posible develar los significados subyacentes en las manifestaciones lingüísticas de los nativos digitales, en la medida en que se sea parte de alguno de los grupos culturales o ciberculturales que los determinan.

Los aspectos anteriores, que por ahora abordan lo lingüístico, también dan cuenta de la necesidad de considerar las manifestaciones lingüísticas de los jóvenes en relación con lo social, a fin de determinar con mayor amplitud o claridad los sentidos que se generan en ellas vinculados, en este caso, con las producciones escriturales.

\subsection{Relación Netspeak, antropología social y mundo de la vida}

Son muchos los autores que han abordado el tema de las NTIC desde un contexto socio-antropológico, entre ellos, Mayans i Planells (2002), quien, desde la historia y la antropología social y cultural, se ha referido a las NTIC especialmente desde la forma en que opera el chat. En su libro , el autor realiza una serie de reflexiones en las que se evidencia el carácter creativo de la lengua, en tanto que es armonizada y recreada por el usuario, lo que se constituye en un fenómeno lingüístico y social.

Mayans i Planells (2002), afirma que los discursos y narrativas sobre las Tecnologías de la Información y la Comunicación, y sobre el ciberespacio, se presentan en mass-media "tradicionales". A través de varios ejemplos, intenta mostrar de qué modo estas construcciones culturales afectan la percepción del nuevo espacio social, como, por ejemplo, en este caso, el ciberespacio, en donde no hay gestos, no hay voz, no hay miradas..., sólo un teclado con el cual, sin embargo, los usuarios se han comprometido a sacar el máximo partido; para ello, juegan con el medio. Aprovechan la expresividad de las letras, alargando vocales, mezclando mayúsculas y minúsculas, recortando palabras, imitando jergas, etc.

Es por esto que la antropología social ve las NTIC situán- dolas, desde el papel de lo local, frente a la globalización, la economía, la política y la cultura. De esta forma, las define como un nuevo contexto socio-tecnológico que trae consigo una gran ventaja para lo local, y no como una amenaza que pretende excluir al ser humano de su entorno o su contexto social; así contradice la opinión de los tecnófobos que afirman que la revolución de la NTIC ha desencadenado una serie de problemas para el ser humano y, por ende, para la sociedad, como el de la inmediatez.

En esta dirección, Bauman (2008), afirma que la plaga de la sociedad de consumo -y la gran preocupación de los mercaderes de bienes de consumo-, es que para consumir se necesita tiempo. Existe una resonancia natural entre la carrera espectacular del "ahora", impulsada por la tecnología de compresión del tiempo, y la lógica de la economía orientada hacia el consumo. De acuerdo con esto, la satisfacción del consumidor debe ser instantánea, dicho en un doble sentido. Es evidente que el bien consumido debe causar una satisfacción inmediata sin requerir la adquisición previa de destrezas ni un trabajo preparatorio prolongado; pero la satisfacción debe terminar "en seguida", es decir, apenas pasa el tiempo necesario para el con- 
sumo, y ese tiempo se debe reducir al mínimo indispensable.

Esta característica de la inmediatez, y sobre todo de la posibilidad de múltiples conexiones, no se queda sólo en el ámbito del consumo, entendido desde lo económico, sino que ha trascendido al de la comunicación. Así, la velocidad que gracias a las tecnologías tienen los procesos comunicativos en la actualidad, amerita la generación de una serie de estrategias discursivas y de adaptaciones lingüísticas que respondan a la velocidad en la que se produce el intercambio de información. Lo anterior justifica las trasformaciones en la lengua generadas por los jóvenes, quienes conciben la comunicación desde la posibilidad de interacción múltiple e instantánea.

En el caso de los jóvenes, estas manifestaciones lingüísticas están en relación con sus vivencias, con su mundo de la vida. Por mundo se entiende en esta investigación a la totalidad, al globo terráqueo, pero visto como el hogar de los seres humanos, estructurado por una cultura con unas costumbres distintas, con un lenguaje diferente, pero con características similares en su ser de humanos. Se hace referencia al mundo en donde se comparte, en donde se va más allá de la mera sensibilidad subjetiva, de las meras sensaciones visuales o táctiles, es decir, se va a las interpretaciones realizadas por los hombres y las mujeres que lo habitan. Se alude a las vivencias particulares y únicas de los sujetos en relación con otros sujetos.

Schutz y Thomas (2003), al hablar del "sentido común de la vida cotidiana" hacen referencia al modo como los seres humanos comprenden el mundo, entendiéndolos como sujetos actores que vivencian significativamente lo que en él existe y en donde se sienten llamados a actuar, es decir, el mero hecho de vivir en el mundo implica para los seres humanos ser entes activos en el mismo. Así, actuar en el "mundo de la vida cotidiana", tiene que ver con la proyección de la acción y con los motivos que la determinan, toda acción está dotada de sentido por el actor y es él quien responde y da sentido a su accionar y actuar en el mundo de la vida. Sin embargo, no hay que olvidar que, aunque el ser humano oriente sus perspectivas de interpretación y acción desde sus coordenadas subjetivas, está inmerso en un mundo que no le es privado, por el contrario es social e intersubjetivo.

El "mundo de la vida" que interesa en esta investigación tiene que ver con esos actores que a diario se encuentran en las aulas de clase de las instituciones educativas de Medellín. Este mundo de interacción constante que viven los escolares, los cuales, aunque habitan el mismo mundo de sus maestros, en ocasiones se perciben como si hicieran parte de dos mundos ubicados en un mismo lugar, en el cual los mundos también se desencuentran.

En este sentido, Berger y Luckmann (1999), afirman que el lenguaje usado en la vida cotidiana proporciona continuamente las objetivaciones indispensables y dispone el orden dentro del cual adquiere sentido, y en el cual la vida cotidiana tiene significado para cada sujeto; cada individuo vive en un mundo que tiene un nombre geográfico. De esta manera, el lenguaje marca las coordenadas de vida en la sociedad y llena esa vida de objetos significativos (p. 39). Por tal motivo, resulta fascinante adentrarse en el lenguaje con el que los estudiantes cibernautas llenan de sentido su mundo de la vida, en cuanto que dicho mundo trae consigo nuevas formas de comunicación, de interacción, nuevos retos que afrontar, pero también significado, textura de sentido que debe ser interpretada; ya que es un mundo construido por la actividad de interacción de estos chicos y chicas del siglo XXI, y no se debe dejar pasar desapercibido, sino adentrarse en él y analizar los objetos que componen (herramientas, símbolos, etc.) el sistema del Netspeak o lenguaje de la Internet.

\section{Análisis, a propósito de las representaciones de sentido presentes en el Netspeak de los estudiantes medellinenses}

El hecho de que partamos de la idea de que en las formas de lenguaje adoptadas por los estudiantes de algunas instituciones educativas de Medellín no se deba resaltar su estatus de agramatical o de impropiedad para con la lengua, es decir, el hecho de que hayamos establecido una mirada más comprensiva y no sancionatoria de estas formas lingüísticas que aparecen tanto en el ciberespacio como en el contexto escolar, nos ha permitido acercarnos a algunos de los sentidos que se comunican o están implícitos en los usos escriturales de los estudiantes. Así, orientamos el análisis para dar cuenta de algunas representaciones de sentido que hemos podido establecer cuando hay un uso del Netspeak en el contexto escolar, este será el punto que tratará el presente apartado. 


\subsection{Componente estético del Netspeak}

Utilizar el lenguaje de la Internet para los estudiantes tiene sentido, entendiendo sentido como una forma de representar y otorgar significación, en un contexto particular, a los conceptos con los que nos relacionamos, es decir, comprendiendo este concepto como aquello que orienta la subjetividad de cada individuo y hace que las cosas sean importantes; es por esto que para los estudiantes el escribir como lo hacen en las redes sociales y, algunos, en sus producciones escritas en el contexto escolar, tiene sentido porque se sienten ellos mismos, se sienten libres, sin estar sujetos a una norma de escritura específica, como lo afirma uno de los estudiantes entrevistados: "Ese lenguaje es una forma de expresarse y no sentirse como en una clase de español, y me gusta la forma en que se ve escrita y que uno copia con más libertad" (SJ3).

Además, en en el espacio de las redes sociales se pueden realizar las transformaciones y combinaciones que se deseen, lo cual hace del Netspeak algo original, he aquí algunos ejemplos de las afirmaciones de los sujetos: "ps no ze uno ze akonztumbra a la forma de ezkribir q ezcribamoz diferente a loz demaz" (SJ2), o, "ps nada, son o es chevere crear palabras nvas" (SJ3). Para estos estudiantes cibernautas del siglo XXI, el crear y recrear la escritura es fundamental, ya que además de imprimirle un carácter personal, también brinda, para estos estudiantes, un sentido estético o de belleza, en sus palabras, de ahí, lo "chévere" de utilizar el Netspeak en sus escritos: "por que se ve más bonito, mas ordenado o simplemente por pura goma" (SJ4).

El componente estético es una representación de sentido que direcciona a los estudiantes a utilizar el Netspeak en su mundo de la vida cotidiana, pero también implica la importancia del tiempo o la limitación del mismo, es decir, para los estudiantes cibernautas utilizar el Netspeak en sus escritos les ayuda a escribir más rápido, como lo afirma SJ6: "pues, escribo más rapido y no me demoro tanto al escribir y al decir lo que quiero decir". De lo anterior se puede deducir que los estudiantes son producto de un mundo que va mucho más rápido, en donde hombres y mujeres se perciben como seres ajetreados y ávidos de tiempo.

No en vano las sociedades actuales han generado metáforas conceptuales basadas en la relación de tiempo y productividad, que vienen a condicionar las formas en que nos insertamos en las dinámicas productivas. Así, "el tiempo es oro" es una de esas metáforas que implican el máximo aprovechamiento del tiempo. Lo interesante es que esta eficiencia también está presente en las interacciones de los estudiantes, lo cual justifica que en ese afán la lengua sea un vehículo o un instrumento maleable para los propósitos que se buscan: "me parece super chevere porque es una forma mas resumida de escribir palabras largas. Me parece una forma mas moderna. Por que así no tenemos que escribir palabra tan largas" (SJ8).

Es en este mundo ajetreado de la era digital, en donde los estudiantes cibernautas encuentran una manera diferente y rápida de comunicación a través del lenguaje y, desde ahí, realizan combinaciones, acortamientos de palabras y demás, que no son simplemente un vicio gramatical, sino que dan cuenta de un nuevo lenguaje que les resulta cómodo, fácil, creativo, novedoso, original y bello, y sobre todo un lenguaje acorde con esta época. Veamos un ejemplo tomado de uno de los estudiantes participantes en la investigación: "pz qe se be todo bonito Que para mi Es como unico ps uno se iDentifica con la leTRa o con los simBolos" (SJ4).

Esta generación del siglo XXI, a la que Prensky ha denominado "nativos digitales", ha dado sentido a su propio lenguaje y ha hecho del Netspeak "otra manera de hablar", con la cual los estudiantes se identifican plenamente en la medida en que se sienten libres; su uso está justificado desde el hecho de que este lenguaje refleja una forma espontanea y vivencial de comunicación, porque a partir de las distintas transformaciones que hacen de la lengua, las diferentes combinaciones de signos de diverso orden, los estudiantes están haciendo presente su ser, su Yo en el aquí y ahora de su historia, en esta era digital. Es decir, estos usos dan cuenta de sujetos históricos que reconocen que sus manifestaciones lingüísticas deben dar cuenta de lo que han construido y de lo que los afecta en tanto sujetos.

Finalmente, para las chicas y los chicos "cibernautas" escribir así tiene sentido, porque va mucho más allá de una mera representación de palabras vacía de contenido, para ellos, como afirma Christlieb (1994), el sentido “[...] siempre estará más allá de las palabras y las imágenes, el sentido es la razón de los sentimientos y los pensamientos, es la experiencia de algo mayor que los símbolos y los significados, que el lenguaje y las imágenes, que el pensamiento y el sentimiento, que hacen que pensar y sentir sirvan para algo" (p. 2004), de ahí que el Netspeak sea útil para estos estudiantes cibernautas, sirve para representar lo "bello". Así, para ellos la belleza del lenguaje está cargada de identidad, de originalidad en su mundo de la vida cotidiana. 


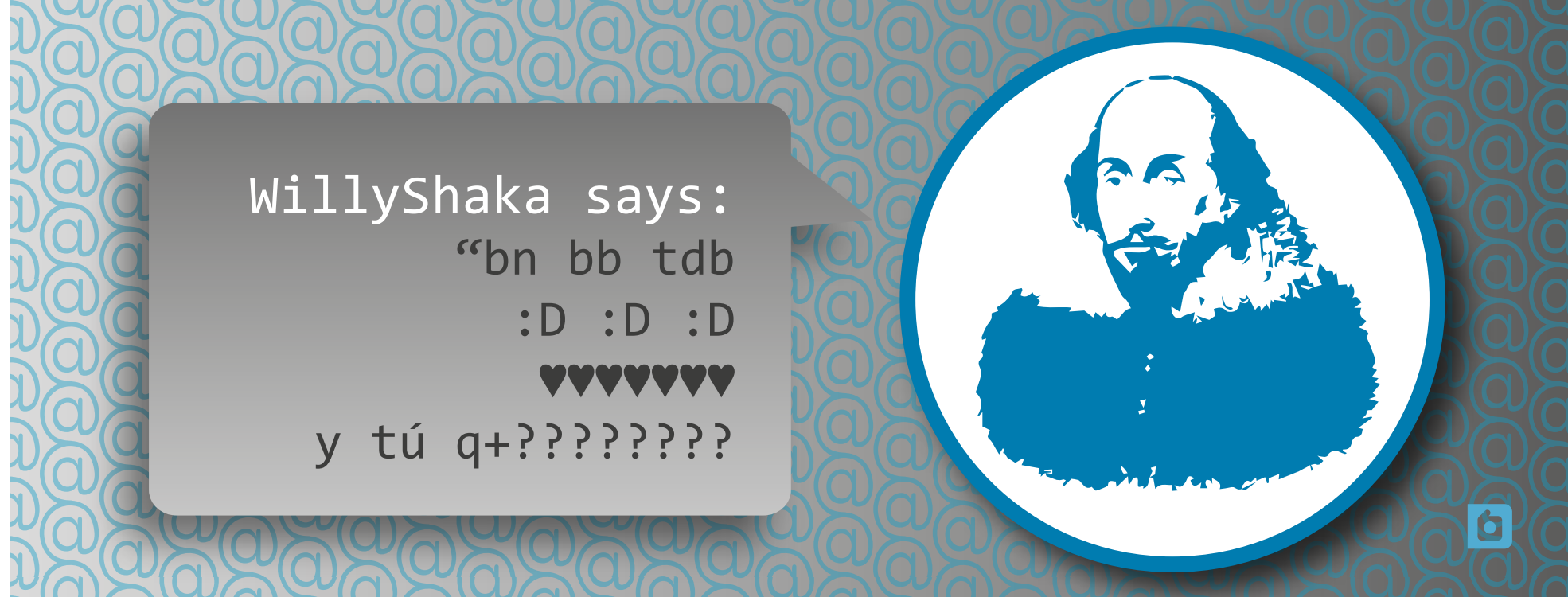

\subsection{Significados del Netspeak en la vida cotidiana de los estudiantes cibernautas}

En esta investigación el significado se entiende desde el punto de vista semántico, es decir, la semántica examina, para este caso, la constitución del Netspeak como fenómeno que produce significado y sentido en la escritura de los estudiantes cibernautas. El netspeak es un nuevo lenguaje que les ayuda a reconocerse como cibernautas, en la medida en que este lenguaje: "se nutre de características que pertenecen por igual a ambos campos de la divisoria oralidad/escritura" (Crystal, 2002, p. 42).

Para los estudiantes cibernautas utilizar el lenguaje de la Internet, además del elemento estético y el temporal, permite vincular a través de la escritura emociones y sentimientos tales como tristeza, alegría, amor etc., lo que se puede apreciar en sus construcciones: “[bn] (bien); [bb] (bebe); [q+] (qué más); [nd] (nada);

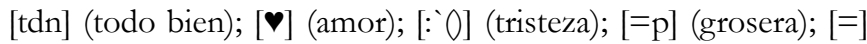
(igual); [(:] (cara feliz); [:/] (confundido); [:3] (tierna); [:‘] (triste, asustado); [:S] (aburrido); [:@] (rabia); [:\$] (pena); [XS] (deprimido)" (S7VB), que para Crystal (2002), es un lenguaje escrito que de alguna manera se ha estirado en dirección del habla (pp. 4243), y, además, en esta investigación se constata que está lleno de matices orales como emoticones, entre otros, los cuales buscan suplir la relación que se da en un encuentro cara a cara.

Pues bien, son muchas las construcciones de los estudiantes cibernautas en sus producciones escritas; sin embargo, el interés de esta investigación solamente se ha centrado en las construc- ciones más usuales en el contexto escolar, por tal motivo vale la pena traer a colación algunos ejemplos: 1) Acortamientos de palabras, los más comunes son "ps", "bn" "tbn" "q"; 2) El cambio de letras o sustitución de una letra por otra, "kual, " $\mathrm{k}=\mathrm{C}, \mathrm{Q}$ "; 3) La utilización de números " $252=$ sisas"; 4) La combinación de mayúsculas y minúsculas "que ayuda a no teneR que escRiBiR paLaBRas Muy Largas” (SJ10); 5) La utilización de la mayúscula al iniciar siempre una palabra en la construcción del párrafo, como se observa en la escritura de SJ4: “es EsQuE La lEtRa mayuscula Toda Casi no Gusta. 1 pz EmpEzando la palaBra con mayuscula y el Resto con minuscula Es maz Bn".

Situaciones como las anteriores son las que permiten afirmar que la utilización de emoticones en los escritos de los estudiantes cibernautas sirve para expresar sus sentimientos frente a la actividad que están realizando, por ejemplo, estas combinaciones de signos [;-)] (feliz); [ᄀᄀ] (mirando rayado); [:O] (asustado); [:S] (aburrido); este agregado de rasgos "hablados-escritos" no es solamente un híbrido generado por la velocidad requerida al momento de escribir, sino que ha de verse como una nueva forma de comunicación que los docentes deberían conocer, especialmente porque al omitir los significados detrás de esta escritura será muy difícil conducirse en ella y mucho más difícil orientar los procesos educativos propuestos en las instituciones escolares.

\subsection{La escritura en los estudiantes cibernautas}

Para la generación del siglo XXI es importante la escritura, especialmente para los y las cibernautas, pues son quienes le dedican gran parte de su tiempo; con ella se comunican, se expresan, por tanto, la mediación de la Internet ha propiciado que esta generación dé importancia capital a esta forma comunicativa, como afirma SJ3: "Me gusta mucho mas ke hablar por Telefono", seguramente

porque es a través de esta escritura que los estudiantes vinculan un elemento como "la oralidad del texto", que, como afirma Yus (2001), es lo más sobresaliente de la comunicación electrónica: la sensación para los usuarios de que escriben lo que desearían estar diciendo y leen lo que les gustaría estar oyendo (2001, p. 12).

$\mathrm{Al}$ respecto, Crystal (2002), afirma que el Netspeak es algo com- 
pletamente novedoso, que motiva a esta generación a permanecer pegada a un teclado de computador, conectada al mismo, pues posibilita al usuario escribir a su gusto y manera, a la vez que escribir más en menos tiempo. En el contexto escolar, algunos transfieren el lenguaje por costumbre o por introyección, de manera consciente o inconsciente; sin embargo, éste se hace sentir en la escritura de los estudiantes cibernautas.

Del mismo modo, para los estudiantes, la escritura además de economizar tiempo en un dictado u otra actividad, se ha adaptado a las diversas necesidades comunicativas, facilitando transmitir el máximo de información en el menor tiempo posible. Este asunto es confirmado por SJ9, cuando afirma que: "que ayuda a no teneR que escRiBiR paLaBRas Muy Largas"; también se observa que esta forma comunicativa está llena de impresiones visuales más llamativas e impactantes para las chicas y chicos cibernautas, en comparación con la escritura tradicional, hecho que se puede constatar con las opiniones de SJ12 y SJ13: "significa una forma nueva de poder hablar, osea no siempre la rutina"; "Sus caritas o los dibujos Que uno puede hacer".

Teniendo en cuenta esta última afirmación es posible destacar que cuando se realiza una diferenciación en "lo que uno puede hacer", se accede a una cierta ventaja de la escritura sobre la voz que, según Yus (2001), se da gracias a la estabilidad de su soporte sobre el papel, la misma que permite una conversación y perpetuación del saber y la experiencia humana (p. 105); es decir, todos esos cambios en la escritura del estudiante cibernauta, que se entremezcla con imágenes, gráfías y demás, se imponen al sonido, generan un mayor gusto y, sobre todo, un sentido por lo escritural.

El rasgo de oralidad presente en el Netspeak, según Yus (2001), "[...] responde al intento de comunicar no sólo contenidos, sino matices esenciales de la comunicación oral como, por ejemplo, la actitud proposicional del emisor hacia el texto que ha tecleado en su pantalla" (p. 98); de ahí que los estudiantes respondan como los sujetos SJ12: "significa una forma nueva de poder hablar" y SJ14: "solo al hablar así escribiendo con cambios de letras". Para los estudiantes cibernautas el Netspeak es una forma de escribir con rasgos orales, sin desconocer que "la escritura se sitúa en el espacio de la representación visual duradera", mientras que el habla lo hace en el espacio destinado a los discursos efímeros; en la mente de los estudiantes cibernautas el Netspeak es una forma de escribir-hablar.

\section{Consideraciones finales sobre el Netspeak y las representaciones de sentido}

Resulta interesante analizar las representaciones de sentido generadas por los estudiantes medellinenses al utilizar el Netspeak en sus producciones escritas, porque de alguna manera ellos le han dado a este lenguaje su propio sentido, lo han direccionado del contexto virtual al contexto escolar. El lenguaje digital o Netspeak (Crystal, 2002), se hace evidente en la forma de pensar, interpretar y escribir de los estudiantes, por lo mismo, vale la pena analizar e interpretar las características del lenguaje digital y las representaciones de sentido que generan los niños, adolescentes y jóvenes en su diario vivir. Además, también es importante reflexionar sobre los aspectos culturales y pedagógicos presentes en el uso del Netspeak, cuando transciende las fronteras de la Internet al contexto comunicativo-educativo.

Es en este siglo XXI donde las nuevas generaciones han creado sus propias representaciones sociales, es decir, han construido su identidad, sus propias formas de comportamiento, de comunicación verbal y escrita, y le han dado sentido y significado; de ahí que el Netspeak o lenguaje de la Internet y las representaciones de sentido se hayan convertido en tema de investigación e incluso de preocupación, por lo cual, según Crystal (2002), se han desarrollado una serie de libros y antologías que abordan el tema del lenguaje de la Internet.

Por otro lado, no hay que olvidar que las nuevas tecnologías de la información y la comunicación son medios que pueden ser utilizados por el ser humano, como lo hacen muy bien los estudiantes del siglo XXI, quienes las aprovechan para procesar en "paralelos y en multi-tareas", y para recrear sus vivencias y la manera como entienden lo social a través de la escritura con el Netspeak, donde pueden incluir emoticones y números, realizar combinaciones de palabras, etc. Además, utilizan estos medios para jugar y aprender, comunicarse e informarse y navegar a una gran velocidad. De igual forma, se puede afirmar que las representaciones generadas por los estudiantes medellinenses al utilizar el Netspeak en sus producciones escritas, tienen sentido porque los representa, les facilita la comunicación de una manera más rápida e imprime un sello personal de identificación, porque se sienten libres, más creativos. 


\section{Referencias}

Bauman, Z. (2008). Turistas y vagabundos. Romanyá Valls S. A: Katz.

Berger, P., y Luckmann, T. (1999). La construcción social de la realidad. Buenos Aires: Amorrortu.

Christlieb, F. (1994). La psicología colectiva, un fin de siglo más tarde. Barcelona: Anthropos.

Crystal, D. (2002). Lenguaje e internet. Madrid: Cambridge.

Galeano, M. E. (2003). Diseño de proyectos en la investigación cualitativa. Medellín: Universidad Eafit.

Jodelet, D. (1986). La representación social: fenómenos, concepto y teoría. En Moscovici, Serge (Comp.). Psicología Social II. Pensamiento y vida social. Psicología social y problemas sociales. Barcelona: Ediciones Paidós.

Martínez, H., y Mora, E. (2008). La identidad lingüística y los trastornos del habla. Boletín de Lingüistica, Vol. 20, No.29, 85-101.

Martínez Miguélez, M. (2004). Ciencia y arte en la metodología cualitativa. México: Trillas.
Mayans i Planells, J. (2002). Genero chats. Cómo la etnografía puso un pie en el ciberespacio. Barcelona: Gedisa.

Moscovici, S. (1984). Psicología social II. España: Paidós.

Palazzo, M. G. (2009). El ciberdiscurso juvenil: representaciones sociales del desconcierto, la censura y la aceptación”. En Espéculo: Revista de Estudios Literarios 41. Obtenido desde http://www.ucm.es/info/especulo/numero41/ciberdis.html.

Piscitelli, A. (2009). Nativos digitales. Dieta cognitiva, inteligencia colectiva y arquitecturas de la participación. Argentina: Santillana.

Prensky, M. (2001). Digital Natives Digital Immigrants. On the Horizon, Vol. 9, No. 5.

Schutz \& Thomas. (2003). Las estructuras del mundo de la vida. Buenos aires: Amorrortu.

Yus, F. (2001). Ciberpragmática. El uso del lenguaje en Internet. Barcelona: Editorial Ariel. 
Tema: Nuevos Lenguajes y Educación

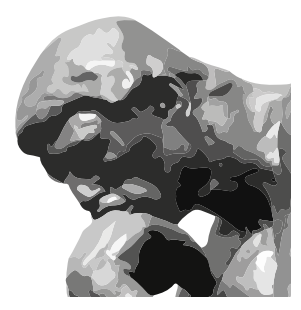

144 Educación y Ciudad No25 Julio - Dictembre de 2013 ISSN 0123-0425 pp. 133-144 